\title{
Retórica contrastiva/intercultural: aplicaciones didácticas a partir del uso de marcadores discursivos en un ensayo por aprendientes eslovenos de ELE
}

Palabras clave: ELE, aprendientes eslovenos, retórica intercultural, marcadores discursivos, aplicaciones didácticas

\section{Introducción: la retórica contrastiva y la retórica intercultural}

La retórica contrastiva es una disciplina de la linguiística aplicada que nació hace medio siglo, cuando Kaplan (1966) comparó los párrafos escritos por estudiantes universitarios hablantes nativos de inglés y de otros orígenes, llegando a la conclusión de que los aprendientes de segundas lenguas transferían los patrones retóricos y culturales de su lengua materna a la lengua meta. Desde el comienzo, el principal interés de la retórica contrastiva fue que sus investigaciones redundaran en aplicaciones didácticas para la clase de lengua extranjera. La disciplina evolucionó con el paso del tiempo y estuvo siempre acompañada por las críticas, lo que ha desembocado en los últimos años en una redefinición del campo bajo el nombre de retórica intercultural. Connor (2011) establece que los estudios actuales deben prestar mayor atención al contexto completo en el que los textos se crean, la presencia en ellos de elementos de diferentes culturas (grandes y pequeñas) y el proceso de negociación de significado que se da en la comunicación intercultural ${ }^{1}$.

1 Para consultar más sobre la transición de una a otra disciplina y las características de ambas véase Heredero Zorzo (en prensa). 


\section{Resultados de nuestro estudio}

Desde los orígenes de esta disciplina una gran cantidad de estudios llevados a cabo con este enfoque se han centrado en el estudio de ensayos escritos por estudiantes universitarios provenientes de diferentes culturas. Junto a esto, muchas de las investigaciones han puesto su foco de atención en la comparación del uso de marcadores discursivos, ya sea en este tipo de textos o en otros géneros relativamente similares. Tal es el caso de trabajos como los de Balažic Bulc (2005) o Deza Blanco (2007).

Heredero Zorzo (2016) aúna estas dos vertientes para contrastar el empleo que hacen de marcadores discursivos estudiantes universitarios nativos españoles y aprendientes eslovenos de español del mismo nivel de estudios en un ensayo expositivo-argumentativo. La muestra estaba compuesta por quince participantes para cada grupo. Los hablantes nativos eran estudiantes de primer y segundo año de la Facultad de las Artes y las Letras de la Universidad Nebrija de Madrid (España), mientras que los universitarios eslovenos cursaban el tercer curso de Filología Hispánica en la Universidad de Liubliana (Eslovenia), disponiendo de un nivel de español situado entre el B2+ y el C2 según el Marco Común Europeo de Referencia para las Lenguas. Los primeros realizaron la tarea en una sesión de clase de ochenta minutos. Por su parte, los aprendientes eslovenos de español como lengua extranjera (en adelante, ELE) la hicieron en casa a lo largo de dos semanas, lo que podría explicar parte de los resultados. En ambos casos, los textos fueron recogidos a lo largo de la última semana de noviembre y la primera de diciembre de 2015 .

El objetivo de la investigación, con un diseño de descripción focalizada, era ver cuánto, cómo y por qué usan los marcadores discursivos los aprendientes eslovenos de ELE. Para ello, se propuso la redacción de un ensayo expositivoargumentativo sobre el tema del español como lengua mundial. En la muestra se compararon concretamente diez categorías de marcadores discursivos: aditivos, causales, conclusivos, consecutivos, contraargumentativos, ejemplificadores, explicativos, organizadores de la información, reforzadores de la información y tematizadores. Los datos fueron procesados con el programa PSPP y sometidos a un análisis cuantitativo y cualitativo.

Por lo que respecta a los números totales, los resultados muestran que ambos grupos utilizan una cantidad relativamente similar de marcadores discursivos. Los hablantes nativos utilizaron de media 11,07 marcadores discursivos por texto, por 12,07 en el caso de los aprendientes eslovenos. Esta diferencia, 
que no confirma la hipótesis previa de que los nativos utilizarían más, podría deberse a la mayor longitud de los textos escritos por los aprendientes eslovenos (estos presentaban una media de 340 palabras, lo que contrasta con las 257,27 empleadas por los universitarios españoles), así como al diferente contexto en el que se realizó la escritura. En el siguiente gráfico se pueden ver los números totales para cada marcador discursivo de la muestra. A la izquierda podemos ver los datos correspondientes a los hablantes nativos, cuyo corpus recibió la etiqueta de Corpus ESP, mientras que a la derecha tenemos Corpus SLO, el formado a partir de los textos producidos por los aprendientes eslovenos.

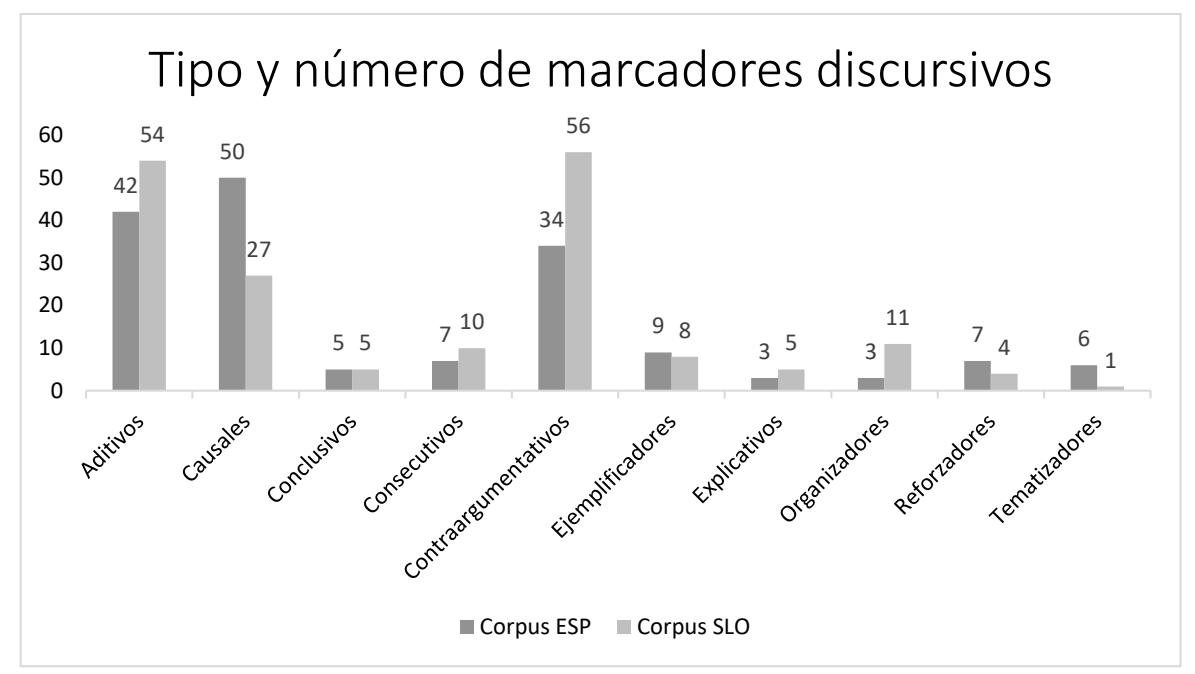

Gráfico 1. Tipo y número de marcadores discursivos empleados en nuestro estudio

Se puede observar que, en relación con cada categoría de marcadores discursivos, los números fueron también relativamente similares, exceptuando los de tipo causal y contraargumentativo, en los que las diferencias resultaron estadísticamente significativas. En cuanto a los marcadores discursivos causales, las estructuras que presentan una mayor diferencia de uso a favor de los hablantes nativos son ya que ( 25 casos entre los nativos y 2 entre los eslovenos) y debido a (9 y 2, respectivamente). Por su parte, dentro de los marcadores contraargumentativos, de mayor empleo entre los estudiantes eslovenos, no se observa ninguna diferencia destacable en relación con ninguna estructura concreta. En cambio, esto sí ocurre en otras categorías que no presentan diferencias estadísticamente significativas. Es el caso de los marcadores de tipo 
conclusivo, donde tenemos en conclusión ( 4 y 1 casos, respectivamente) y para concluir (o y 2). En lo referente a los marcadores consecutivos sucede con por (lo) tanto, empleado 4 veces por los nativos y solo en 1 ocasión por los eslovenos, quienes, en cambio, utilizan de manera incorrecta los marcadores orales asíque (en 4 ocasiones) y entonces ( 2 veces), los cuales no aparecen entre los nativos. En relación con las estructuras que sirven para organizar la información, llama la atención que los hablantes nativos se decantan al principio del texto por primero, que aparece en 1 ocasión, y los eslovenos prefieren para empezar, con 3 casos. Un fenómeno similar ocurre con este tipo de marcadores al final del texto, con los españoles optando por por último y los eslovenos por para terminar, siendo ambas estructuras utilizadas 1 vez. Finalmente, también destacamos que los aprendientes eslovenos apenas hacen uso de marcadores discursivos tematizadores, apareciendo solo en cuanto en 1 ocasión. Por su parte, los hablantes nativos la emplean 5 veces (si bien en determinados casos de manera inapropiada), además de 1 presencia de respecto $a$. En la siguiente tabla resumimos estas diferencias relevantes en el uso de marcadores discursivos entre uno y otro grupo y que podrían tener una repercusión en aplicaciones didácticas.

\begin{tabular}{|l|l|l|}
\hline Marcador discursivo & Corpus ESP & Corpus SLO \\
\hline ya que & 25 & 2 \\
\hline debido a & 9 & 2 \\
\hline en conclusión & 4 & 1 \\
\hline para concluir & 0 & 2 \\
\hline por (lo) tanto & 4 & 1 \\
\hline asíque (oral) & 0 & 4 \\
\hline entonces (oral) & 0 & 2 \\
\hline primero & 1 & 0 \\
\hline para empezar & 0 & 3 \\
\hline por último & 1 & 0 \\
\hline para terminar & 0 & 1 \\
\hline en cuanto a & 5 & 1 \\
\hline respecto a & 1 & 0 \\
\hline
\end{tabular}

Tabla 1. Diferencias relevantes para aplicaciones didácticas en el uso de marcadores discursivos 
Consideramos que estas divergencias podrían tener diversas consecuencias en la recepción de los textos por parte de una comunidad discursiva nativa en la que los estudiantes eslovenos de Filología Hispánica quisieran integrarse. Por ello, estimamos oportuna una intervención didáctica por parte de los profesores que subsane estas imprecisiones. El objetivo de este trabajo es establecer las bases de dichas aplicaciones didácticas a partir de diferentes acciones recomendadas por investigaciones previas de retórica contrastiva e intercultural para que en un futuro se pudiera llevar a cabo tal intervención pedagógica.

\section{Aplicaciones didácticas generales en la retórica intercultural}

Como hemos mencionado más arriba, la retórica contrastiva/intercultural tuvo desde sus orígenes una clara orientación pedagógica. No obstante, si se analiza la bibliografía existente al respecto, llama poderosamente la atención que las investigaciones que acaban resultando en aplicaciones didácticas concretas o que giran en torno a ellas son escasas. Los estudios se centran principalmente en las diferencias y similitudes entre ambas lenguas y culturas escritas sin 1legar a proponer acciones determinadas para facilitar la producción de textos a los aprendientes de una lengua meta, lo que resulta una fuerte contradicción respecto a los propósitos de la disciplina. Con esto coincide Walker (2006: 94), quien decía que el campo presentaba carencias «in development and application to classroom study». En cualquier caso, existen determinados trabajos que sí cumplen este objetivo. Estas aplicaciones pedagógicas de la retórica intercultural, parte de las cuales han sido recogidas por Connor y Traversa (2014), son presentadas a continuación.

Cuando un pedagogo con un enfoque retórico intercultural se sienta a diseñar actividades que puedan ayudar a los aprendientes a adaptar sus procesos de escritura y sus productos escritos a las expectativas de la comunidad discursiva a la que pretenden dirigirse, frecuentemente llegan a una primera idea común. Esta no es otra que la de exponer a los estudiantes a textos equiparables en ambas lenguas maternas, es decir, si tenemos, por ejemplo, un grupo de aprendientes eslovenos les presentaríamos escritos comparables (en contenido, audiencia, grado de pericia del escritor, canal de comunicación...) en lengua eslovena y en lengua española que hayan sido escritos por hablantes nativos. A esta misma idea ya llegó Casanave (2004). Junto a ello, con el fin de prestar la debida atención al contexto en el que se crean los textos, esta investigadora también propone que el profesor estimule entre los estudiantes el análisis de 
los objetivos de su escritura y la audiencia a la que va dirigida, así como las expectativas de esta, con la intención de «breaking down students' stereotypes of their $L_{1}$ and $L_{2}$ and helping them come to a more complex understanding of how their $L_{1}$ rbetoric creates meaning» (Casanave 2004: 46). Casanave (ibidem) aconseja que, para profundizar en la reflexión de las expectativas de la audiencia, los aprendientes pueden reaccionar a textos escritos con el mismo objetivo comunicativo en ambas lenguas y así discutir sobre las expectativas culturales respecto a determinados productos escritos. Además, según Matsuda (1997), los estudiantes deberían aprender estas negociaciones experimentando el proceso de una forma real, es decir, realizando tareas en contextos reales de escritura en comunidades discursivas con lectores verdaderos. Siguiendo este punto de vista, este autor propone como actividad escribir una reseña crítica del ensayo de un compañero y compartirlo con toda la clase.

Para los investigadores del campo, la discusión en la clase respecto a la escritura y lo que le rodea es fundamental. Por ello, es una aplicación didáctica que ha estado presente desde los tiempos iniciales de la disciplina, como muestra la investigación llevada a cabo por Liebman (1988). Esta investigadora desarrolló un curso en el que concibió a los estudiantes como "etnógrafos" y promovió el debate entre estudiantes nativos y no nativos de inglés acerca de la forma en la que escribían. La autora afirma que «not only students from botb clases learned to write, but they learned a great deal about otber cultures» (Liebman 1988: 18). Estos postulados han tenido amplio eco en trabajos posteriores, como en Kubota y Lehner (2004), quienes intentaron reformular la disciplina bajo el nombre de retórica contrastiva crítica incluyendo elementos postestructuralistas, postcoloniales y postmodernos para intentar paliar la supuesta aculturación de los estudiantes al aprender inglés como lengua extranjera. Si bien esta corriente ha quedado descartada, resultan oportunas las recomendaciones de que el estudiante reflexione de manera crítica sobre las convenciones retóricas establecidas tanto en su lengua materna como en la lengua extranjera, así como su relación personal con dichas convenciones. Estos autores sugieren que los estudiantes piensen y discutan sobre estos aspectos en relación con su idioma nativo y transfieran de manera crítica estas percepciones a la hora de producir textos en la lengua meta. Tanto el enfoque de Liebman (1988) como el de Kubota y Lehner (2004) seguirían a la perfección los postulados de la retórica intercultural, ya que, como afirma Connor (2011: 64), «for the classroom, the new intercultural rbetoric theory has an impact on bow we treat students' L1 cultures and their new culture, how we view norms and expectations of language, and bow we deal with students' identities». 
Así pues, se puede observar que la reflexión crítica y el debate sobre las diferentes convenciones retóricas en la clase de lenguas extranjeras es de vital importancia para la retórica intercultural. Para Liebman (1988), estas discusiones deberían ir acompañadas de las tradicionales lecciones magistrales del profesor. Esto también es apoyado por Yoshimura (2002), quien además concluye que la mejora en la escritura de los estudiantes es aún mayor si la instrucción se realiza en la lengua materna de los aprendientes. La instrucción tradicional por parte del docente, combinada con actividades centradas en la respuesta de los estudiantes, también es apoyada parcialmente por Walker (2011). Este autor hace un repaso de diferentes publicaciones que muestran que las conferencias de los profesores fomentan una mayor reflexión entre los estudiantes, mientras que en lo referente a las actividades de respuesta entre los compañeros existe división de opiniones. No obstante, propone que se realicen este tipo de tareas (preferiblemente en parejas) para que los estudiantes analicen características específicas de su propia escritura. Sugiere que estas actividades deben ser numerosas y centradas en los aprendientes y que de esta manera los estudiantes adquirirán una mayor conciencia acerca de la audiencia a través de la retroalimentación de sus compañeros, desarrollarán el pensamiento crítico al analizar y revisar la escritura de otros y reforzarán la confianza en su propio trabajo, gracias a la observación de primera mano de las dificultades que los compañeros tienen al escribir. Finalmente, Walker (2011) recomienda que el profesor dirija el debate en la clase, guiando a los alumnos hacia el tratamiento de la forma de aprendizaje de la retórica en su lengua materna, las dificultades que encuentran a la hora de desentrañar las ideas en la retórica de los textos de la lengua meta y los ajustes necesarios para satisfacer las expectativas de la audiencia en la lengua extranjera cuando escriben en ella. En su trabajo de guía, el docente puede hacerse valer de rúbricas, listas de comprobación y preguntas que sirvan de guía. Walker (2011: 78) sugiere que, así, «students may respond better to intercultural rbetoric if they are allowed to make discoveries for themselves».

Estas prácticas pedagógicas también se pueden llevar a cabo a través de las nuevas tecnologías, tal y como demuestra el trabajo de Xing, Wang y Spencer (2008). Estos autores implementaron un curso de telecolaboración entre hablantes nativos de inglés y aprendientes chinos de esta lengua con la intención de mejorar la expresión escrita de estos últimos. Para ello, idearon un curso colaborativo, puesto que «learning to compose in a foreign language is not an isolated classroom activity, but a social and cultural experience» (Xing, Wang y Spencer 2008: 73). Las herramientas para establecer la telecolaboración fueron salas de chat, correos electrónicos, foros de debate y, ocasionalmente, 
videoconferencias. El curso tuvo una duración de diez semanas, se centraba en determinados aspectos (estructura textual, uso de marcadores discursivos, párrafos...) y los estudiantes tenían que dedicarle al menos 20 minutos a la semana y escribir un ensayo cada dos semanas. Para esto último, primero tenían que presentar un primer borrador en el foro de debate, pudiendo así ser visto y comentado por todos los compañeros y el profesor. Una vez realizada la discusión sobre el texto, debían elaborar la versión final del mismo, la cual también era cargada a la plataforma para que todos los participantes tuvieran la oportunidad de observarla y apreciar las mejoras. Asimismo, los estudiantes tenían a su disposición en el campus virtual modelos en ambas lenguas en los cuales estaban resaltados de diferentes formas aquellos aspectos en los que se centraba el trabajo de la semana (por ejemplo, si el tema era el uso de los marcadores discursivos, estos estaban marcados con diferentes colores) y unas actividades dirigidas a la reflexión del alumno respecto a estos elementos lingüísticos y textuales. De esta manera, los aprendientes podían observar, comparar y analizar diferentes materiales de las dos culturas, intercambiando puntos de vista de una manera recíproca y, por consiguiente, profundizando en su análisis intercultural. Los resultados de la investigación mostraron que los participantes no nativos modificaron su estilo de escritura hasta equipararlo al de los hablantes nativos. Del mismo modo, los participantes mostraron en una encuesta de satisfacción tras el experimento que el curso les había resultado positivo debido a la interacción, si bien consideraban que esta no era mejor entre compañeros que con hablantes nativos y con profesores y deseaban una comunicación más frecuente, así como una mayor cantidad de materiales de muestra.

Por lo que respecta al ELE, los trabajos de este tipo son muy escasos. Prácticamente solo podemos hablar del realizado por Jiménez Ramírez (2010). Este investigador puso en práctica un tratamiento pedagógico similar a los ya comentados con la intención de mejorar la aplicación de los símbolos ortotipográficos por parte de estudiantes universitarios en España procedentes de diferentes culturas. La aplicación pedagógica consistió en comparar estos elementos en un cuento bilingüe español e inglés, es decir, usando modelos originales de los productos escritos y debatiendo acerca de las similitudes y las diferencias. Los resultados de la investigación mostraron que hubo una mejora en el empleo de estos elementos por parte de los aprendientes, lo que se evaluó a través de entrevistas personales con ellos y la calificación por parte de profesores externos. 


\section{Aplicaciones didácticas a nuestro caso de estudio}

Las aplicaciones didácticas expuestas más arriba servirían para mejorar la expresión escrita de los aprendientes de ELE, puesto que, según Connor (2011: 77), un enfoque intercultural «trains learners to view different cultures from a perspective of informed understanding», dotando a los estudiantes de mayores opciones a la hora de tomar una determinada decisión retórica. Debido a ello, a continuación establecemos una serie de tratamientos pedagógicos concretos aplicados a nuestro estudio del uso de marcadores discursivos en un ensayo expositivo-argumentativo por parte de aprendientes eslovenos de ELE que presentábamos más arriba.

Obviamente, debido a que en nuestra investigación escribieron el mismo ensayo estudiantes universitarios nativos y aprendientes eslovenos de ELE, la primera aplicación didáctica que propondríamos sería comparar la escritura de unos y otros respecto al uso de los marcadores discursivos que presentan mayores divergencias y que hemos enumerado anteriormente. Así, podríamos exponer a los universitarios eslovenos a fragmentos (no sería necesario el texto entero para este caso concreto) de los ensayos escritos por nativos y por ellos mismos y guiar la reflexión sobre las diferencias de uso (también podría hacerse para observar las similitudes). Por ejemplo, en el caso de las estructuras causales podríamos mostrarles los dos extractos siguientes, correspondientes el primero a un escritor nativo y el segundo a uno esloveno ${ }^{2}$ :

[1] Debido a su facilidad, utilidad, es la lengua de internet y a que la cultura inglesa y americana, etc son mundialmente conocidas y compartidas, su uso no deja de crecer. También debemos mencionar que en estos territorios también se habla y estudia el español, ya que para ellos es su lengua secundaria y su vehículo de aprendizaje y de empleo.

[2] En primer lugar, creo que en la Edad Moderna el uso de las lenguas se difunde a través de la tecnología y los medios. En este aspecto el inglés tiene una gran ventaja en comparación con el español porque es la lengua oficial del Internet, los programas y los ordenadores en general.

2 Tanto [1] y [2], como los fragmentos posteriores [3] y [4], están extraídos de David Heredero Zorzo (2016). En todos ellos se respeta la grafía del original, incluso si es incorrecta. Tómense estos fragmentos como ejemplos de lo que se podría llevar a cabo. No es nuestro objetivo aquí plantear una exhaustiva serie de comparaciones entre los dos corpus. 
Una vez que los alumnos hayan leído ambos fragmentos, se podría iniciar la discusión preguntándoles qué texto está escrito por un nativo y por qué lo piensan, debatiendo acerca de ello. Después, se les pediría que busquen en ambos ejemplos estructuras a partir de las cuales el lector establece inferencias causales. De esta manera, se vería que en [1] aparecen debido a y ya que, mientras que en [2] tenemos porque. Entonces, el profesor les preguntaría cuáles son las diferencias pragmáticas en el uso de estos marcadores, guiando el debate entre los estudiantes, el cual terminaría cuestionándoles qué conectores serían más apropiados para este tipo de texto y por qué. El profesor simplemente ejercería el papel de guía, dejando el peso de la discusión a los alumnos y haciendo notar determinados aspectos que les pudieran pasar inadvertidos a estos, siguiendo lo establecido por Liebman (1988) y Walker (2011).

El mismo procedimiento se podría poner en práctica respecto al resto de marcadores discursivos mencionados en el apartado 2 de este trabajo. Así, para trabajar las estructuras que sirven para organizar la información (más concretamente para introducir una última aportación) se podrían usar los siguientes fragmentos, siendo [3] escrito por un hablante nativo y [4] por uno aprendiente esloveno:

[3] Por último, también la posición del español respecto a otras lenguas se ha visto manifestada en las redes sociales, constituyendo el tercer idioma más hablado después del chino y el inglés.

[4] Y para terminar, si nos fijamos en el dominio digital (el internet) alguna vez leí en alguna parte del mismo que el castellano es la tercera lengua de comunicación entre los usuarios y [...].

Este tratamiento pedagógico respecto a los marcadores discursivos podría ser completado con el uso de otros textos escritos por hablantes nativos en ambas lenguas, como propone Casanave (2004). De esta manera, se les presentarían ejemplos de textos en español y en esloveno que se podrían sumar al debate iniciado con los escritos producidos por los estudiantes. Este análisis se centraría, en nuestro caso concreto, en los marcadores discursivos empleados, pero, dependiendo de las necesidades de nuestro curso, el trabajo podría ampliarse a otros aspectos como la estructura del texto o la división de los párrafos. A continuación, presentamos un ejemplo de dos fragmentos a comparar en ambas lenguas ${ }^{3}$ :

3 Ambos textos corresponden a un modelo de comentario de texto literario de la prueba de acceso a la Universidad en España y Eslovenia, respectivamente. En primer lugar, [5] está 
[5] Las ideas de Iturrioz, es decir, es imposible cambiar la crueldad humana y hay que restringir la lucha a cuestiones concretas, aparecen razonablemente argumentadas; no obstante, la conclusión de Andrés de que lo mejor es no hacer nada, creo que no tiene un sustento sólido en las palabras del texto, porque igual que opta por esa conclusión u opción podía haber sacado otra bien distinta.

[6] Pomembno slogovno sredstvo v odlomku je, tako kot v celotni drami, igra svetlobe in teme. Maks privije luč, saj, kot pravi, noben morivec še ni moril pri luči. Tudi njegove besede v poltemi zvenijo drugače. Ko Kantor zgrabi Krnca za vrat, Maks prekine dogajanje s tem, da luč privije navzgor in razsvetli prostor, pa tudi spregovori z drugačnim glasom.

Respecto a [5] y [6] el profesor podría guiar el debate entre los alumnos de manera que se fijen en los marcadores discursivos que aparecen y las inferencias que se establecen a partir de ellos, si hay algunos comparables, qué implica el uso de unos y otros en ambas lenguas, etc. Con esta reflexión, se pretende conseguir un mayor conocimiento de estas estructuras en ambas lenguas.

Por último, consideramos que estas aplicaciones didácticas obtendrían sus mejores resultados si se implementaran a través de un curso de telecolaboración al estilo del planteado por Xing, Wang y Spencer (2008). Con tal fin, se crearía una plataforma virtual en la que, a lo largo de varios meses, estudiantes eslovenos y universitarios nativos de español compartirían trabajo y experiencias. Los contenidos de dicho curso se acercarían mucho a los propuestos por Xing, Wang y Spencer (2008). Así, habría diferentes secciones: marcadores discursivos, diversos géneros discursivos, estructura textual, tratamiento del párrafo,

extraído de Universidad de Granada (2008): Solucionario a las pruebas de acceso a la Universidad propuestas por las universidades andaluzas: http://www.ugr.es/ eues/pau/PruebasPAU2008/ asignaturas/lengua_cast_lit/4Texto\%2ode\%2oPio\%2oBaroja.pdf (6-9-2016). Por su parte, [6] está tomado de VV. AA. (2013): Esej na maturi 2014. Človek v svetu. Ljubljana: Intelego. Consideramos comparables ambos textos por tener autores de características equiparables, el mismo propósito comunicativo, incluirse dentro de una comunidad discursiva similar y corresponder al mismo género. El tema también es relativamente parecido, ya que analizan un texto literario, que, a su vez, podría tener ciertas similitudes temporales, estilísticas y temáticas (en el caso español se trata de El árbol de la ciencia, publicado en 1911 por Pío Baroja, mientras que en el caso esloveno es Kralj na Betajnovi, publicada en 1902 por Ivan Cankar). Obviamente la comparabilidad es bastante subjetiva, especialmente en lo referente a textos literarios, pero considérese como un ejemplo posible. Hay que tener en cuenta la dificultad de encontrar textos de estas características en lengua española y eslovena que resulten equiparables. 
etc. Para cada sección habría unos materiales de trabajo y unos modelos sobre los cuales los participantes deberían reflexionar. Cada estudiante esloveno estaría emparejado con un universitario nativo, con el cual podría debatir acerca de los materiales de cada sección por videoconferencia o correo electrónico, así como con el resto de alumnos a través de foros. Cada apartado tendría una tarea final, que consistiría en una producción escrita, la cual podría ser individual o trabajada por las parejas predeterminadas de nativo y no nativo. Idealmente, estas tareas serían reales y necesitarían una respuesta por parte de un miembro del curso o, incluso, por un actor externo. Como ejemplo de tarea escrita real, proponemos la redacción de una carta de solicitud de admisión para estudios de máster en una universidad española. Primero, se redactaría un borrador, que sería colgado y comentado por todos en la plataforma para promover aún un mayor debate acerca de las elecciones retóricas de unos y otros, repercutiendo en un mayor dominio de las mismas. Finalmente, se elaboraría una versión final del texto que también sería compartida con todos los participantes del curso en la plataforma para una evaluación final por parte de los compañeros y del profesor. Una vez terminado el curso, se realizarían encuestas de satisfacción y entrevistas con los participantes, con el fin de averiguar la valoración de los estudiantes sobre el mismo. Consideramos que este tipo de tratamiento pedagógico sería muy útil para los hablantes no nativos a la hora de mejorar su competencia escritora, pero, a diferencia de lo que pudiera parecer, también para los universitarios nativos, a cuya escritura no se le presta la debida atención en numerosas ocasiones y también es claramente mejorable, como se puede apreciar en el corpus de nuestro estudio ${ }^{4}$.

\section{Conclusiones}

A lo largo de este trabajo hemos visto cómo uno de los fines de la retórica intercultural es desembocar en aplicaciones pedagógicas para la clase de lengua extranjera, aunque esto no ha ocurrido siempre con la deseada frecuencia. Asimismo, hemos afirmado que los aprendientes eslovenos de ELE de nivel universitario emplean los marcadores discursivos de manera similar a como lo hacen los universitarios nativos, si bien el uso de determinadas estructuras se podría mejorar, como debido a y por (lo) tanto, entre otras. Con este fin, hemos propuesto diferentes tratamientos pedagógicos que siguen la línea de

4 Más arriba, hemos mencionado el uso incorrecto que hacen los hablantes nativos de nuestra muestra del marcador discursivo en cuanto a. Otro aspecto claramente mejorable es la división en párrafos, la cual en algunos casos es inexistente. Los textos de la muestra se pueden consultar en Heredero Zorzo (2016). 
las aplicaciones establecidas desde la retórica intercultural, con autores como Liebman (1988), Casanave (2004), Xing, Wang y Spencer (2008) y Walker (2011), que consistirían en el contraste de textos escritos en ambas lenguas maternas, en lengua española tanto nativa como meta y un curso telecolaborativo entre hablantes nativos y no nativos en el que se incluyeran conceptos como los marcadores discursivos, la estructura de los géneros o el tratamiento del párrafo. Consideramos que este tipo de enfoque ayudaría a progresar a aprendientes de ELE, así como a nativos, en su competencia escritora, especialmente en la toma de conciencia respecto a la tipología textual. De igual manera, estimamos que fomentaría el empleo del aprendizaje colaborativo y provocaría una mayor difusión de la disciplina conocida como retórica intercultural. Por todo ello, y debido a la escasez de este tipo de intervenciones pedagógicas dentro de la lingüística aplicada, presenta un amplio panorama de práctica que es necesario desarrollar en el futuro.

\section{Bibliografía}

Balažic Bulc, T. (2005): «Connectors in Students'Academic Writing in Two Closely Related Languages (on the Case of Slovene and Croatian Language)». En: Universidad de Birmingham, Proceedings from the Corpus Linguistic Conference Series Vol. 1-2. Birmingham: Centre for corpus research: <http://www.birmingham.ac.uk/Documents/college-artslaw/ corpus/conferencearchives/2005-journal/ContrastiveCorpusLinguistics/ Connectorsinstudentsacademicwriting.doc (30-11-2015).

Casanave, C. (2004): Controversies in second language writing: Dilemmas and decisions in research and instruction. Ann Arbor: University of Michigan Press.

Connor, U. (2011): Intercultural Rhetoric in the Writing Classroom. Michigan: Universidad de Michigan.

Connor, U., Traversa, A. (2014): «The Role of Intercultural Rhetoric in ESP Education». 4th CELC Symposium Proceedings: http://www.nus.edu. $\mathrm{sg} / \mathrm{celc} / \mathrm{research} /$ books/4th\%2 OSymposium $\% 2$ oproceedings/3).\%20 Connor\%2oand\%20Traversa.pdf (4-9-2016).

Deza Blanco, P. (2007): «Los conectores en noticias de sucesos. Retórica contrastiva en textos de periodistas españoles y alumnos taiwaneses». Círculo de lingüística aplicada a la comunicación: http://pendientedemigracion. ucm.es/info/circulo/no3o/deza.pdf (28-4-2015). 
Heredero Zorzo, D. (2016): «El uso de marcadores discursivos en el género ensayo. Análisis de producciones escritas de estudiantes eslovenos desde la Retórica Contrastiva». Biblioteca virtual redELE 17.

Heredero Zorzo (en prensa): «De la retórica contrastiva a la retórica intercultural. Una nueva vuelta de tuerca al análisis contrastivo de la expresión escrita». Madrid: Universidad Nebrija.

Jiménez Ramírez, J. (2010): «Cómo aumentar la calidad de la producción escrita en la clase de E/LE: introducción a la retórica contrastiva mediante las diferencias ortotipográficas». En: ASELE, XXI congreso internacional de ASELE. Del texto a la enseñanza-aprendizaje del español L2-LE. Salamanca: ASELE, 265-273.

Kaplan, R. B. (1966): «Cultural Thought Patterns in Inter-Cultural Education». Language Learning, 16, 1-20.

Kubota, R., Lehner, A. (2004): «Toward Critical Contrastive Rhetoric». Journal of Second Language Writing, 13, 7-27.

Liebman, J. (1988): «Contrastive rhetoric: Students as etnographers». Journal of Basic Writing, 7 (2), 6-27.

Matsuda, P. K. (1997): «Contrastive Rhetoric in Context: A Dynamic Model of L2 Writing». Journal of Second Language Writing, 6 (1), 45-60.

Walker, D. (2006): «Improving Korean university student EFL academic writing with contrastive rhetoric: Teacher conferencing and peerresponse can help». Journal of Asia TEFL, 3 (4), 71-111.

Walker, D. (2011): «How to Teach Contrastive (Intercultural) Rhetoric: Some Ideas for Pedagogical Application». New Horizons in Education, 59 (3), 7181.

Xing, M., Wang, J., Spencer, K. (2008): «Raising students' awareness of crosscultural contrastive rhetoric in English writing via an e-learning course». Language Learning and Technology, 12 (2), 71-93.

Yoshimura, T. (2002): Formal instruction of rbetorical patterns and the effectiveness of using the $L_{1}$ in argumentative writing in an EFL setting. [Tesis doctoral inédita] Temple University Japan. 
David Heredero Zorzo

Institute OUTJ Polhov Gradec

\section{Didactic Applications of the Use of Discourse Markers in an Essay by SFL Slovenian Learners}

Keywords: SFL, Slovenian learners, intercultural rhetoric, discourse markers, didactic applications

Contrastive rhetoric, nowadays redefined as intercultural rhetoric, was born half a century ago with the main purpose of analysing second language learners' writing in order to propose pedagogical applications that would help to improve it. However, classroom treatments have not been developed as often as they should have. In this paper, we revise the main pedagogical directives established by intercultural rhetoric and we apply them to a case study where we compare the use of ten categories of discourse markers in an expositiveargumentative essay written by Spanish native University students and Slovenian learners of SFL. Even though we reach the conclusion that students from Slovenia use these structures in a similar way to that of the native speakers, we consider that a pedagogical intervention is appropriate to correct some differences. We therefore propose a classroom debate to compare texts from the case study and the contrast of texts written in both mother tongues, as well as the implementation of a telecollaborative course between native speakers and Slovenian University students, which would aid the understanding of discourse markers and other aspects of Spanish usage. 
David Heredero Zorzo

Zavod OUTJ Polhov Gradec

\section{Kontrastivna / medkulturna retorika: raba diskurzivnih označevalcev $\mathbf{v}$ pisnih sestavkih esejskega tipa slovenskih učencev španščine kot tujega jezika in njihova uporaba pri poučevanju}

Ključne besede: poučevanje španščine kot tujega jezika, slovenski učenci, medkulturna retorika, diskurzivni označevalci, uporaba pri poučevanju

Kontrastivna retorika, ki jo danes opredeljujejo tudi z izrazom medkulturna retorika, se je pojavila na prelomu druge polovice prejšnjega stoletja. Njena osnovna namena sta bila proučiti pisno izražanje študentov španščine kot tujega jezika in ponuditi ustrezne pedagoške pristope, ki bi pripomogli k izboljšanju omenjene spretnosti. Kljub zastavljenim izhodiščem je bil obseg pristopov pri poučevanju tujega jezika, ki so nastali v okviru kontrastivne retorike, skromen. Pričujoči prispevek ponuja ponoven razmislek o nekaterih temeljnih smernicah poučevanja $\mathrm{v}$ okviru medkulturne retorike ter omenjeni razmislek podpre $\mathrm{z}$ raziskavo, $\mathrm{v}$ kateri je primerjalno predstavljena raba desetih kategorij diskurzivnih označevalcev v razpravljalnih pisnih izdelkih esejkega tipa v španščini univerzitetnih študentov - naravnih govorcev španščine - ter slovenskih študentov, ki se španščine učijo kot tujega jezika. Kljub ugotovitvi, da je raba diskurzivnih označevalcev pri slovenskih študentih španščine na primerljivi ravni z rabo v skupini naravnih govorcev, prispevek podpira tudi smiselnost uvajanja ustreznih pedagoških pristopov pri tistih vidikih rabe označevalcev, kjer je bil zaznan znaten odstop med skupinama. Med ustreznimi pedagoškimi pristopi prispevek ponudi razpravo v razredu na temo primerjave med obravnavanimi besedili iz raziskovalnega korpusa ter ugotavljanje razlik med besedili v obeh maternih jezikih, španščini in slovenščini, ter uvajanje računalniško podprtega sodelovalnega učenja diskurzivnih povezovalcev in drugih vsebin v skupinah s slovenskimi študenti španščine kot tujega jezika ter španskimi študenti. 